\title{
Três passos em direcção à maturidade
}

Daniel Pinto*,António Faria-Vaz**, Bruno Heleno*, Isabel Santos****

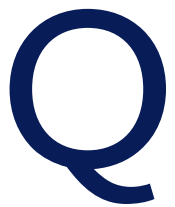
uando aceitámos o desafio e a responsabilidade de fazer parte da equipa editorial da Revista Portuguesa de Clínica Geral (RPCG) era nosso desejo assegurar as funções fundamentais necessárias ao seu funcionamento e que conduzem à sua publicação regular, mas, também, inovar em alguns aspectos cruciais.

O primeiro passo aconteceu na organização interna da equipa editorial. Criou-se um conjunto de ferramentas que permitem uma gestão mais coordenada e eficaz dos manuscritos em processo de revisão e o delinear do circuito interno dos artigos. Este conjunto de ferramentas irá reduzir o tempo que medeia entre a recepção de um manuscrito enviado pelos autores e a sua publicação na revista.

Do segundo passo damos conta neste número da revista - a revisão das normas para apresentação de artigos à RPCG. A necessidade de proceder a esta tarefa surgiu nos primeiros meses do nosso trabalho, ao verificarmos que, dentro do próprio Conselho Editorial, não havia consenso em torno das normas vigentes. Nos últimos anos da revista poucos foram os artigos em que as normas foram respeitadas na íntegra. Assim, foram sendo feitas pequenas adaptações por cada um dos editores e dos revisores. Estas permitiram assegurar a publicação regular da revista, mas, dentro do corpo editorial, estabeleceu-se uma sensação de mal-estar. Por um lado, estas adaptações eram uma injustiça para com os autores que se esforçavam por adaptar os seus manuscritos às normas da RPCG e, por outro, esta conduta prejudicava a estratégia definida para conduzir à indexação da revista.

A motivação para a actualização das normas emana da necessidade de as harmonizar com as normas internacionais relativas à publicação de manuscritos em biomedicina ${ }^{1} \mathrm{e}$ com as normas éticas relativas à publi-

\footnotetext{
*Editor Associado da Revista Portuguesa de Clínica Geral

**Director da Revista Portuguesa de Clínica Geral

***Editora da Revista Portuguesa de Clínica Geral
}

cação de estudos de investigação que envolvam seres humanos (declaração de Helsínquiaª e Convenção sobre os Direitos do Homem e da Biomedicina - ratificada pela Assembleia da República ${ }^{3}$ e decretada pela Presidência da República ${ }^{4}$ em 2001). Em consequência dessa harmonização são apuradas as regras de conduta dos autores (autoria, conflitos de interesse e fontes de financiamento) e as normas relativas à salvaguarda do cumprimento dos valores éticos que devem presidir e orientar a investigação que envolva seres humanos (o primado do ser humano, a avaliação ética independente e a garantia da dignidade do ser humano e do respeito pelos os direitos e liberdades fundamentais da pessoa).

A elaboração das novas normas para apresentação de artigos à RPCG foi um trabalho que nos deu particular prazer pelo muito que aprendemos com os grupos internacionais que se debruçam sobre esta matéria. Começámos por estudar as normas de algumas das principais revistas médicas mundiais (New England Jornal of Medicine, ${ }^{5}$ Annals of Internal Medicine, ${ }^{6}$ British Medical Journal ${ }^{7} \mathrm{e}$ Annals of Family Medicine $)^{8} \mathrm{e}$ daí partimos para a rede EQUATOR ${ }^{9} \mathrm{e}$ as diversas normas de orientação para cada tipo de estudo. Tivemos, é certo, que adaptar as recomendações destas organizações à realidade nacional da Medicina Geral e Familiar. Optámos, em muitos casos, por apontar aos autores um determinado caminho a seguir, sem fazer exigências excessivas face à nossa realidade, que poderiam pôr em perigo a própria existência da revista. Não queremos, porém, deixar de assinalar que a obrigatoriedade do cumprimento do que por agora são apenas recomendações será desejável num futuro próximo. Não pretendemos com estas exigências dificultar a publicação de trabalhos na nossa revista, mas antes contribuir para a melhoria qualitativa da produção científica nacional na área da Medicina Geral e Familiar. Assim, para os manuscritos que já se encontram em processo de revisão e para os trabalhos que tenham sido concluídos até à 
publicação destas normas, os autores poderão solicitar aos editores que prescindam de algumas das exigências agora instituídas, quando o seu cumprimento implicar refazer o estudo. Esses pedidos serão analisados pelo Conselho Editorial caso a caso e aceites apenas quando devidamente justificados. Aos autores que se encontram a preparar manuscritos para submeter à RPCG recomendamos a leitura atenta das normas que agora publicamos.

Entretanto, estamos também a preparar o terceiro passo, que permitirá melhorar a relação da revista com os seus leitores e torná-la mais atractiva para os autores. Estamos a desenvolver um novo sítio na internet que permitirá que o processo de revisão decorra onli$n e$, facilitando o trabalho dos editores e dando aos autores a possibilidade de saber o estado do seu manuscrito em qualquer momento. Talvez mais importante, o sítio permitirá que a informação acerca dos artigos publicados seja fornecida a serviços de indexação como o «Directory of Open Access Journals», aumentando substancialmente a divulgação da RPCG em todo o mundo. A indexação da revista em bases de dados como a Scielo Portugal, MEDLINE, EMBASE e outras continua a ser uma das nossas prioridades. Porém, o caminho até à indexação é uma prova de obstáculos. Esperamos que um deles tenha sido ultrapassado com a publicação das novas normas para apresentação de artigos à RPCG.

\section{REFERÊNCIAS}

1. International Committee of Medical Journal Editors [página na Internet]. Uniform Requirements for Manuscripts Submitted to Biomedical Journals: Writing and Editing for Biomedical Publication [acedido em 17/02/2009]. Disponível em: http://www.ICMJE.org

2. Williams JR. Revising the Declaration of Helsinki. World Medical Journal 2008 54(4):120-5.

3. Resolução da Assembleia da República n. ${ }^{\circ}$ 1/2001, de 3 de Janeiro. Diário da República, I Série-A p.14-36.

4. Decreto do Presidente da República $n^{\circ} 1 / 2001$, de 3 de Janeiro. Diário da República, I Série-A p. 14.

5. NEJM:Author Center Help [Página na Internet]. Boston: New Eng J Med; 2009 [acedido em 2009/02/28]. Disponível em: http://authors.nejm.org/Help/acHelp.asp

6. Ann Intern Med: Information for Authors [Página na Internet]. American College of Physicians; 2007 [acedido em 2009/02/28]. Disponível em: http://www.annals.org/shared/author_info.html

7. BMJ: Article requirements [Página na Internet]. London: BM]; c20002009 [acedido em 2009/02/28]. Disponível em: http://resources.bmj.com/bmj/authors/article-submission/article-requirements

8. Ann Fam Med: Information for Authors [Página na Internet]. Cleveland: Annals of Family Medicine, Inc [acedido a 28/02/2009]. Disponível em: http://www.annfammed.org/misc/ifora.shtml

9. The EQUATOR Network. Enhancing the Quality and Transparency of Health Research [homepage on the Internet]. Oxford: Minervation Ltd; [actualizado em 2008/04/24; acedido em 2009/02/28]. Disponível em: http://www.equator-network.org/ 